\title{
Analysis of Functional Group Sited on Multi-Wall Carbon Nanotube Surface
}

\author{
Rike Yudianti ${ }^{*}, 1$, Holia Onggo ${ }^{1}$, Sudirman ${ }^{2}$, Yukie Saito ${ }^{3}$, Tadahisa Iwata ${ }^{4}$ and Jun-ichi Azuma ${ }^{5}$ \\ ${ }^{I}$ Research Center for Physics - Indonesian Institute of Sciences (LIPI), Jalan Cisitu No. 21/154D Bandung 40135, \\ Indonesia \\ ${ }^{2}$ Department of Chemistry, University of Indonesian, Kampus Baru UI, Depok, Indonesia \\ ${ }^{3}$ Department of Global Agricultural Sciences, University of Tokyo, 1-1-1-Yayoi, Bunkyo-ku, Tokyo 113-8657, Japan \\ ${ }^{4}$ Department of Biomaterial Sciences, Graduate School of Agricultural and Life Sciences, University of Tokyo, 1-1-1- \\ Yayoi, Bunkyo-ku, Tokyo 113-8657, Japan \\ ${ }^{5}$ Departement of Enviromental Science, Graduate School of Agriculture, Kyoto University, Sakyo-ku, Kyoto 606-8502, \\ Japan
}

\begin{abstract}
Functionalization of Carbon Nanotube (CNT) plays an important role in creating CNT hybride material. In this study, integrated analysis of functional group sites on the pristine and modified Multi-Wall Carbon Nanotube (MWCNT) surface was comparably conducted to know the effect of acid solution on the surface after purification and functionalization process. Acid treatment removed rest of graphitic and residual catalytic metal particles and suffered degradation, such as nanotube shortening and additional defect generation in the graphitic network. Defects on the side wall due to functionalized group clearly shown in Transmission Electron Image (TEM) images cause a reduction in thermal stability. Functional group sited on the side wall was detected by Attenuated Total Reflectance (ATR) - Fourier Transform Infra Red (FTIR) with the relative concentration of oxygen-containing functional groups determined by Boehm titration.
\end{abstract}

Keywords: Carbon nanotube, Functionalization, Graphitic particle, Transmission electron microscope, Fourier transform infrared spectroscopy.

\section{INTRODUCTION}

Carbon nanotubes (CNTs) have received considerable attention as a new class of nanomaterials since their discovery in 1991 [1, 2]. CNTs display their unique physical, chemical, electronic [3,4] and mechanical properties [5]. The properties of CNTs have attracted the attention and interest of researchers of many fields for applications as batteries, hydrogen storage and tools in nanotechnology, gas sensors [6], optoelectronic devices [7] and catalytic application [8].

However, the homogeneous dispersion of CNTs is relatively difficult to achieve. Carbon nanotubes tend to form long bundles that thermodynamically stabilized by numerous $\pi-\pi$ interactions [9] and Van der Waals binding energy about $500 \mathrm{eV} \mu \mathrm{m}^{-1}$ of tube-tube contact [10]. Most of the techniques have been used to disperse these bundles, e.g., ultrasonication, addition of surfactant [11] and chemical modification of the nanotube surface [12], as susceptible way to break down or at least to perturb the extended delocalized $\pi$ system.

Surface functionalization of carbon nanotubes plays an essential role for improving the solubility and dispersion of

*Address correspondence to this author at the Research Center for Physics Indonesian Institute of Sciences (LIPI), Jalan Cisitu No. 21/154D Bandung 40135, Indonesia; Tel: +62 22 2503052; Fax: +62 22 2503050;

E-mail: rikeyudianti@yahoo.com the nanotubes in aqueous solutions and to design new hybrid materials [13-15]. Functional groups attached on the carbon surface are found to responsible for the various physicochemical and catalytic properties of the matter. The oxygen-containing functional group could be introduced by mechanical [16], chemical [17] and electrochemical routes [18]. It is known that the amount and type of oxygencontaining functional groups depends on the treatment methods. Many researchers focussed on how to modify it as well as to characterize the surface functional group of carbon material in order to improve their practical application.

Recently, we presented the analysis of oxygen-containing group anchored on carbon surface after chemical oxidation, as now well established and efficient method to functionalize MWCNTs. To this purpose, nitric acid was selected as one of the most frequently used agent in oxidation of CNT. Stepwise purification in low concentration of acid solution successfully removed graphitic and metal catalytic particles. Functionalization process under a stronger acid solution power caused introduction of different number of oxygenated acidic surface group onto the carbon surface. Oxygenated acidic surface group of pristine, purified and functionalized MWCNT was comparably evaluated. Identification of oxygenated acidic surface group was performed by ATR - FTIR as qualitative technique for evaluation of the chemical structure of CNT. Identification of ill-organized hexagonal carbon in the order hexagonal 
carbon and density of carboxyl and total oxidized groups at MWCNT surface will be performed by Raman spectroscopy and quantitatively analyzed with Boehm titration method.

\section{EXPERIMENT}

\subsection{Stepwise Purification of MWCNT}

Pristine MWCNT used in this study was purchased from Chengdu Alpha Nano Tech. Co. Ltd. Stepwise purification of pristine MWCNT was thermally and chemically performed as steps prevented self-poisoning by foreign impurities. Thermal oxidation at $550^{\circ} \mathrm{C}$ in air flowing for 30 min was done to remove amorphous carbon. Loss of mass is $0.8-1.3 \%$. The chemical purification was consecutively performed with $6 \mathrm{M}$ hydrochloric $(\mathrm{HCl})$ and nitric acid solution $\left(\mathrm{HNO}_{3}\right)$ under stirring for 3 hours. After $6 \mathrm{M} \mathrm{HCl}$ treatment, washing, filtration and finally drying in air were subsequently carried out. Thereafter, $6 \mathrm{M}$ nitric acid solution $\left(\mathrm{HNO}_{3}\right)$ was also subjected to the samples under stirring for 3 hours and then used a same way of washing, filtration and drying. The sample was assigned as purified MWCNT.

\subsection{Functionalization of MWCNT}

In the further step, functionalization of purified MWCNT was carried out with reflux in $1: 3 \mathrm{v} / \mathrm{v}$ a mixture of sulfuric $(10 \mathrm{ml}, 95-97 \%)$ and nitric acid $(30 \mathrm{ml}, 65 \%)$. Prior to the process, purified MWCNT was sonicated in mixture of acid solution for 2 hours to open agglomeration of nanotube and anchoring acid solution uniformly on the carbon surface. Thereafter, homogenized carbon solution was oxidized under reflux at $100^{\circ} \mathrm{C}$ for 6 hours to introduce functional group. Five-fold dilution was then applied to the carbon solution to stop oxidation reaction. Stirring and decantation were consecutively conducted for five times and finally washed with deionized water by filtration until the water $\mathrm{pH}$ approximately at 7 . Precipitate was finally dried in vacuum oven at $60^{\circ} \mathrm{C}$, assigned as functionalized MWCNT.

\subsection{Analysis of Functional Groups}

Analysis of morphological surface of carbon nanotube was performed by Transmission Electron Microscope (TEM), JEOL JEM 1200 EX and Scanning Electron Microscope (SEM), JEOL JSM-6360LA. The sample $0.5 \mathrm{mg}$ was prepared using ultrasonication in ethanol solution for 2 hours, dropped onto the surface of TEM grid or SEM holder and allowed to dry in air. Thermal analysis of MWCNT was conducted by Thermal Analyzer, Mettler Toledo Star System with ASTM E 1131 to evaluate purity level of MWCNT. The measurement was conducted by heating of $5-5.2 \mathrm{mg}$ samples in platinum pan $(5 \mathrm{~mm}$ in diameter), under oxygen flow in temperature range of 35 up to $1000^{\circ} \mathrm{C}$ at $10^{\circ} \mathrm{C} \mathrm{min}$.

Progressing of oxygen-containing functional groups was identified by Attenuated Total Reflectance - Fourier Transform Infrared (ATR FT-IR, Shimadzu prestige-21) spectroscopy. The surface of ATR was cleaned by methanol before the sample was applied to ensure the infrared reflecting medium, germanium $(\mathrm{Ge})$, was not polluted. After methanol evaporated completely, the powder of sample was covered with the infrared reflecting medium and fixed on ATR-FTIR.
Analysis of order-disorder hexagonal carbon was recorded by a Raman-microspectroscopy system with a NRS-3100 spectrometer (Jasco Co., Japan) equipped with a charge-coupled device (CCD) for the phonon detection system. It was operated exciting with the $532 \mathrm{~nm}$ laser radiation under objective lens of $\times 20$ magnification with a slit of $1 \times 6 \mathrm{~mm}$. The exposure time was 30 s and three scans were accumulated for each spectrum. All the spectra were recorded at $0.1 \mathrm{~cm}^{-1}$ step intervals at room temperature. To protect from damage by the laser beam, the sample embedded into a $\mathrm{KBr}$ pellet and low power of $1.2 \mathrm{~mW}$ was employed on the sample surface so that no appreciable peak shift or peak broadening caused by the laser heating.

Oxygen functional groups were quantitatively evaluated using the Boehm titration method. Amount of carboxyl and total acidic site on the carbon surface was quantitatively chemical analyzed by titration. Amount of carboxylic and total acidic sites determined by addition of $20 \mathrm{ml}, 0.05 \mathrm{~N}$ $\mathrm{NaHCO}_{3}$ and $\mathrm{NaOH}$, respectively into $5 \mathrm{mg}$ MWCNT and stirred for 48 hours to reach an equilibrium state. Thereafter, the solution was filtrated to remove MWCNT from clear solution. Removal of the MWCNTs from the titrated solution is essential to avoid $\mathrm{HCl}$ reacting with the deprotonated groups at MWCNT surface, which would induce errors as well as slow down the titration. Filtered solution diluted with $80 \mathrm{ml}$ of deionized water. A part of solution $(10 \mathrm{ml})$ was mixed with $(0.05 \mathrm{~N}, 20 \mathrm{ml}) \mathrm{HCl}$ and boiled for 30 min to remove $\mathrm{CO}_{2}$. Finally, the titration was performed by $(0.05 \mathrm{~N}) \mathrm{NaOH}$ solution to determine the excess of $\mathrm{HCl}$ until the neutral solution reached.

\section{RESULTS AND DISCUSSION}

Purification and functionalization treatments give a different effect on density of defect on the surface of carbon nanotube. The differences are revealed on the analysis results of acid treated-MWCNTs characters including purified and functionalized MWCNTs compared with pristine MWCNT character.

\subsection{Thermal Behavior Analysis of MWCNT}

Generally, MWCNTs are complex mixtures of nanotubes and other impurities. Combustion of carbon materials does not occur until temperature reaches at least $400^{\circ} \mathrm{C}$. Weight loss below the temperature can be assigned to the evaporation of water absorbed or the evolution of surface functional groups. Generally, combustion of the nanotubes and the carbonaceous impurities takes place at temperatures above $300^{\circ} \mathrm{C}$, with several band components are usually observed as the derivative TGA (DTG) curve. Pristine MWCNT shows two stepwise combustion temperature at 590.2 and $650^{\circ} \mathrm{C}$ corresponding to carbon nanotube $(80.4 \%)$ and graphitic particles $(10.1 \%)$, respectively (Fig. 1a). On the further heating until $950^{\circ} \mathrm{C}$, MWCNT leaves residue $9.4 \%$, corresponding to catalytic metal particles. After purification, improvement of thermal stability slightly reached, quite well preserved until $613.5^{\circ} \mathrm{C}$ (Fig. 1b) eventhough a decreasing weight was slight clear observed $(4.5 \%)$ as hydrophilic properties of sample. The thermalstable carbon was created due to removal of graphitic and catalytic metal particles by acid solution. No weight 
(a)

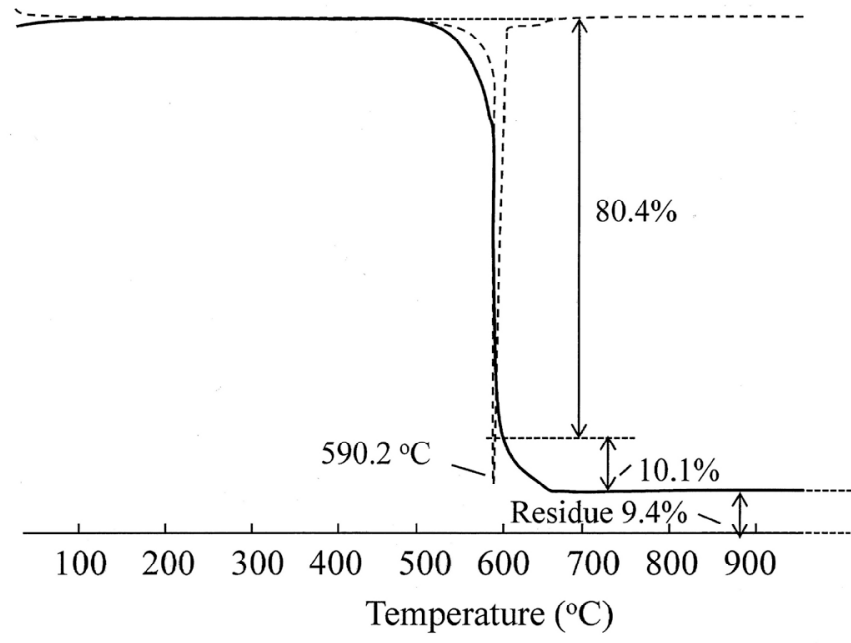

(b)

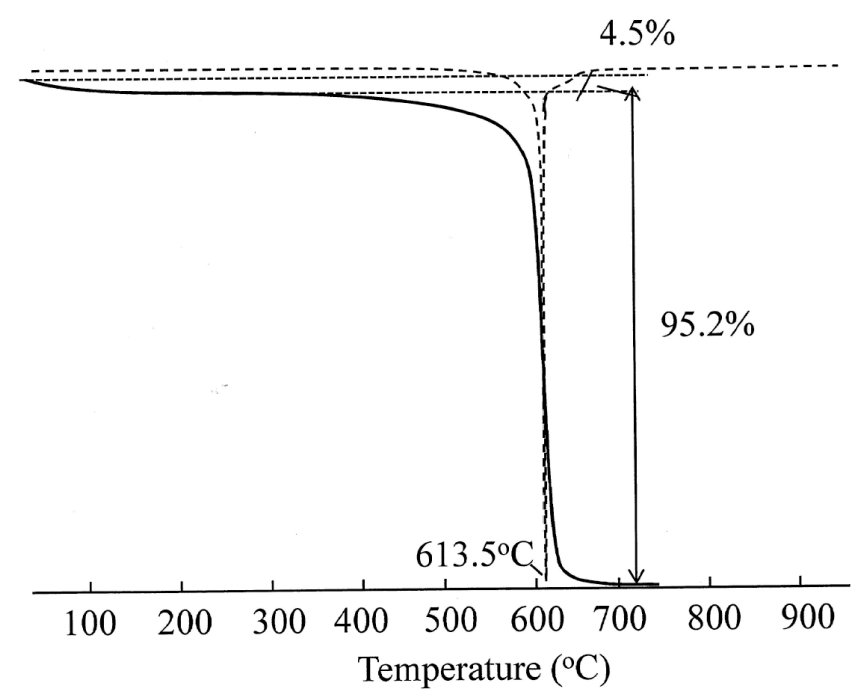

(c)

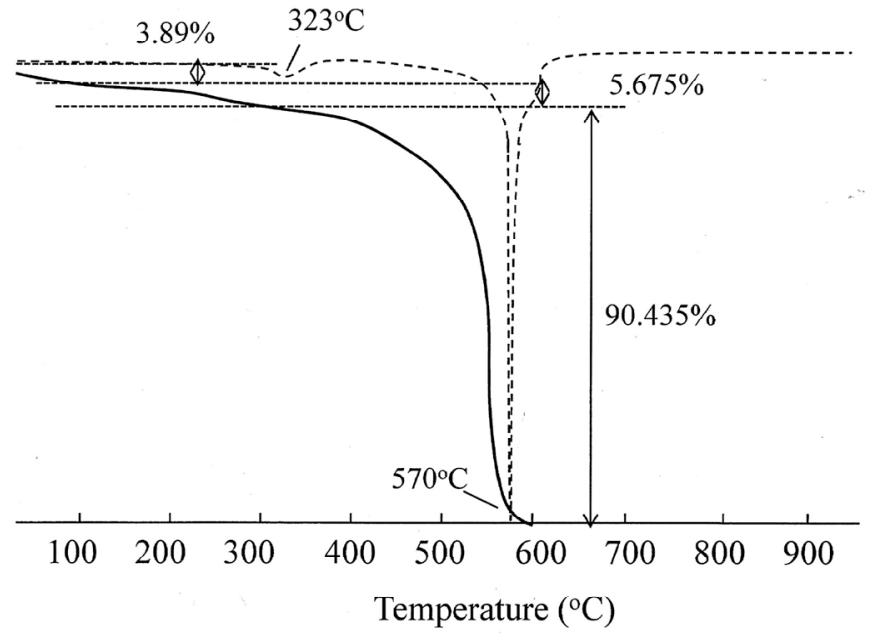

Fig. (1). Thermogravimetric curves of pristine and acid treated MWCNTs. (a) pristine MWCNT, (b) purified MWCNT, (c) functionalized MWCNT reduction appeared untill $600^{\circ} \mathrm{C}$ indicating no amorphous carbon attached on the surface. Huang et al. [19] also successfully removed amorphous carbon by purification process under vacuum condition. After reflux in the stronger power of acid solution, weight reduction (3.89\%) from 90 until $150^{\circ} \mathrm{C}$ was clearly observed in Fig. (1c) indicating improvement in its hydrophilicity. Slow weight reduction under heating $150-323^{\circ} \mathrm{C}$ corresponds to decomposition of functional group $(5.7 \%)$ on the MWCNT surface accompanied with the release of carbon dioxide. Tsukahara et al. [20] stated that weight losses at $150-500^{\circ} \mathrm{C}$ constitutes decomposition of carboxyl group on the carbon surface after sodium hypochlorite treatment under microwave irradiation. While the combustion of carbon nanotube achieved in the further heating untill the maximum weight reduction $90.4 \%$ at $570^{\circ} \mathrm{C}$. Defect generation due to breaking down of carbon double bonding is important factor in reduction of thermal decomposition from $613.5^{\circ} \mathrm{C}$ in purified MWCNT to $570^{\circ} \mathrm{C}$ in functionalized MWCNT.

\subsection{Morphological Surface Analysis of MWCNT}

Fig. (2) shows SEM and TEM images of morphological surface of MWCNT. Prior to purification, some particle impurities attached on the carbon fiber surface as the rest of the synthesis process. They are pointed out by white arrows. Impurities usually in form of graphitic, metal catalytic and amorphous carbon will interfere the potential characters of CNT.

Based on TGA analysis, the particles were identified as metal catalytic particles and carbon allomorph like graphitic particles (Fig. 2a). Detachment of graphitic and metal catalyst particles from the surface was realized by subsequent thermal and acid treatment with average length of nanotube ranges above $2 \mu \mathrm{m}$ length. Stepwise treatment succesfully removed impurities and providing well-dispersed fibers (Fig. 2b). The average length of nanotube seem not changed. Deaglomeration of fiber elucidates reducing in surface tension and bundling system of tubes. Acid treatment also cause errosion of fiber, observed in thinning of the CNT layer by removal of some particles attached on the nanotube surface. Flawless surface in purified condition was clearly observed in TEM image of Fig. (2b), no destruction occured on the side wall. In the stronger power of acid treatment (Fig. 2c), oxidization newly created defect (as indicated by black arrows) which resulted in shorter fiber, estimated 200$500 \mathrm{~nm}$ length [21, 22]. Liu et al., [23] also used mixture of $\mathrm{H}_{2} \mathrm{SO}_{4} / \mathrm{HNO}_{3}$ to cut the highly tangled long fiber of CNTs into shorter, open-ended pipes and thus produced many carboxylic groups at the open end. Zhang et al. [24] stated that acid is known to intercalate and exfoliate graphite in making higher number of oxidation site on carbon atom. The oxidation site might be formed on the side wall and at the end of tube as discussed by Chen et. al. [25]. Based on the all morphological surface analysis, nanotube still clearly visible after functionalization leading to shortening and defect as functional sited. It proves that the acid mixtures enough to generate functional groups sited on the surface. Detail analysis of functional group progress will be more discussed in ATR-FTIR analysis. 
(a)

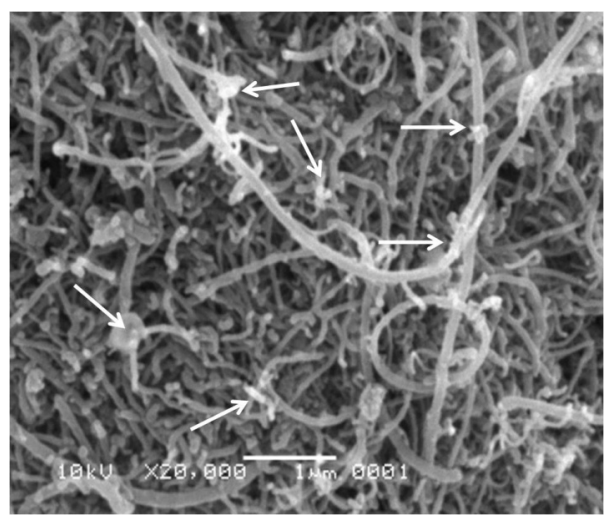

(b)

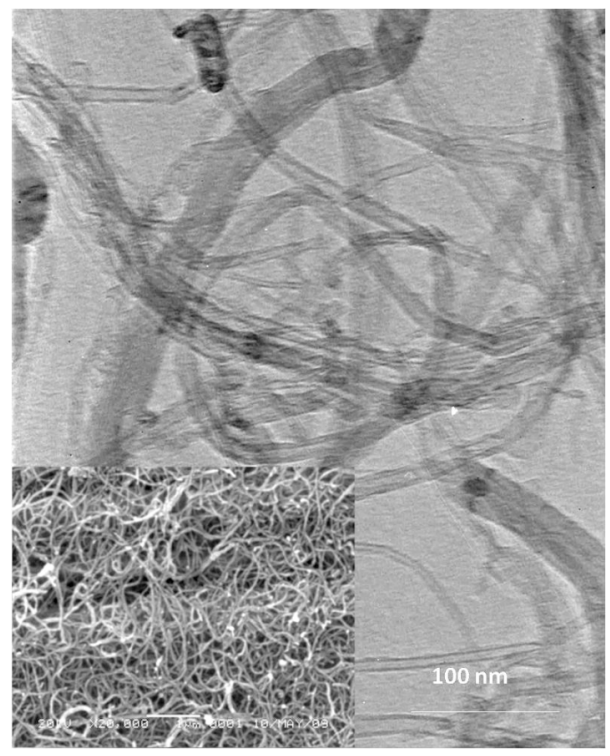

(c)

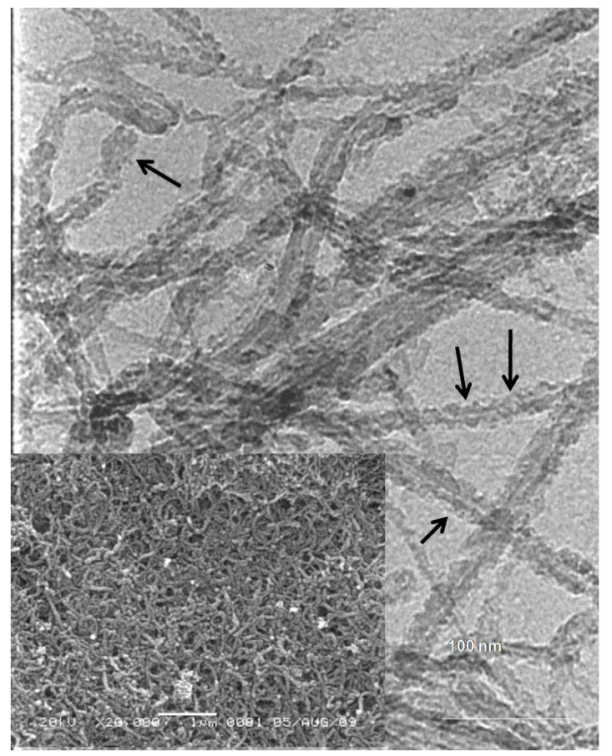

Fig. (2). Scanning and transmission electron microscope images of pristine and acid treated MWCNTs. (a) pristine MWCNT (white arrow: impurities), (b) purified MWCNT, (c) functionalized MWCNT (black arrow: defect generation).

\subsection{Identification of Functional Groups Sited on MWCNT Surface}

FTIR is mainly used as qualitative technique for evaluation of functional group. Fig. (3) shows the Attenuated Total Reflection Infrared spectra of pristine MWNT (Fig. 3a) and acid treated-MWNTs (Fig. 3b, c) from 400 to $4000 \mathrm{~cm}^{-1}$. Noticeable peak at $2800-2900 \mathrm{~cm}^{-1}$ appears after purification and functionalization corresponding to the $\mathrm{C}-\mathrm{H}$ asymmetric and symmetric stretching vibration, derived from long alkyl chain. It reveals the stability of carbon nanotube suspensions in the aqueous phase. Integrity of hexagonal structure on the pristine MWCNT was confirmed in appearance of peak at $1532-1560 \mathrm{~cm}^{-1}$ elucidating existence of carbon double bonding $(\mathrm{C}=\mathrm{C})[26]$. Decreasing the absorbance of $\mathrm{C}=\mathrm{C}$ indicates oxidation of carbon with remarkably emergence of peak at $1753 \mathrm{~cm}^{-1}$ as carbonyl of carboxyl group. Appearance of peak at $1753 \mathrm{~cm}^{-1}$ assigns carbonyl $(\mathrm{C}=\mathrm{O})$ stretching vibration of carboxyl groups $[27$, 28] indicating the expanssion of carboxylation on the surfaces of purified and functionalized MWCNTs. Usage of nitric acid in the purification process causes both, purity improvement as well as partial oxidization of carbon. Number of functional groups should increase after oxidation with a stronger power of sulfuric and nitric acid mixture (Fig. 3c). Acid solution attack double bonding of carbon in decreasing peak region at $1532-1560 \mathrm{~cm}^{-1}$ and the hexagonal carbon at region $500-1000 \mathrm{~cm}^{-1}$. Reducing the intensity of peak elucidates presence of large number of asymetrical hexagonal carbon. The sharp peak at $1640 \mathrm{~cm}^{-1}$ also assigns to carbonyl of quinone type units along the side walls of the nanotubes [29] which decreased after purification and functionalization. Analysis on quantitative functional groups on the carbon nanotube surface was further evaluated by titration.

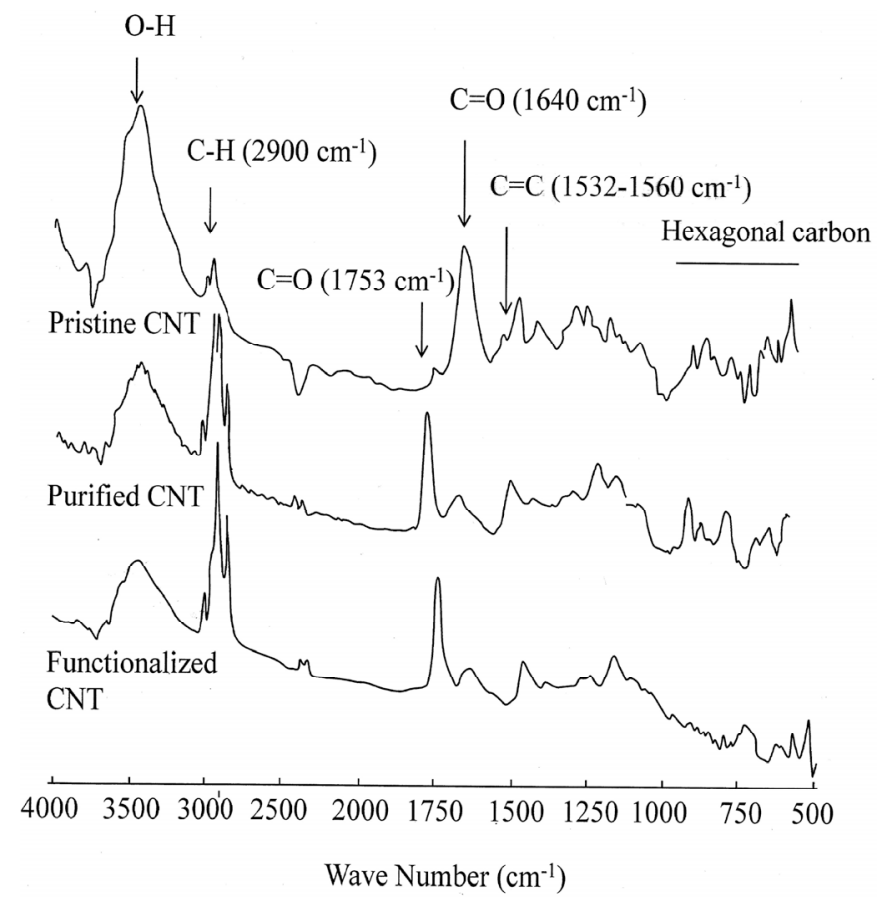

Fig. (3). Attenuated total reflectance - FTIR spectra of pristine and acid treated MWCNTs. 
Table 1. Quantitatif Analysis of Carboxyl and Total Acidic Groups and Estimation of Defect Level

\begin{tabular}{|c|c|c|c|c|}
\hline & Treatment & Total Acidic Group $\left(\mathbf{m m o l}^{-\mathbf{1}} \cdot \mathbf{g}\right)$ & Carboxyl Group $\left(\mathbf{m m o l . g}^{-\mathbf{1}}\right)$ & $\mathbf{I}_{\mathbf{D}} / \mathbf{I}_{\mathbf{G}}$ \\
\hline \hline Pristine MWCNT & - & 2.4 & 1.9 \\
\hline Purified MWCNT & $6 \mathrm{M} \mathrm{HCl}-6 \mathrm{M} \mathrm{HNO}_{3}$ & 15.9 & 0.95 \\
\hline Functionalized MWCNT & $65 \% \mathrm{HNO}_{3}$ and $95-97 \% \mathrm{H}_{2} \mathrm{SO}_{4}$ & 43.9 & 31.6 & 0.76 \\
\hline
\end{tabular}

\subsection{Quantitative Analysis of Carboxyl and Total Acidic Sites on MWCNT Surface}

Quantitatif analysis of functional group attached on the carbon surface was conducted by Boehm titration [30]. They elucidate that content of acidic oxygen-containing surface groups per gram of CNT material given as a function of chemical treatment. The various free acidic group was determined based on the assumption that sodium hydroxide neutralizes carboxyl, lactone and phenolic groups as total acidic groups of free acidic carbon while $\mathrm{NaHCO}_{3}$ neutralizes only carboxyl groups $[31,32]$. It replaced $\mathrm{H}^{+}$of surface acid group by $\mathrm{Na}^{+}$causing the acidity of functionalized carbon decreased. The titration experiments demonstrate that acid treatment increases the concentration of carboxyl and acidic surface sites, given in Table $\mathbf{1}$.

Combination treatment of nitric and sulphuric acid significatly contributed in drastical improvement of total acidic groups such as phenolic groups $(-\mathrm{OH})$, lactone group $(\mathrm{C}=\mathrm{O})$ and carboxyl group $(-\mathrm{COOH})$ as well as individual carboxyl group (-COOH).

\subsection{Estimation of Defect Level on Hexagonal Carbon}

Raman spectroscopy is a very valuable tool for the characterization of carbon-based nanostructures. The technique used of this research is to analyze the presence of amorphous in crystalline phases coresponding to differences in graphitizations. Graphitization of pristine, purified and functionalized MWCNT was comparatively analyzed based on destruction level due to acid treatment (Fig. 4). They relatively have two major peaks at $1325 \mathrm{~cm}^{-1}$ as D-band and at $1530 \mathrm{~cm}^{-1}$ as G-band. The frequencies at around $1325 \mathrm{~cm}^{-1}$ and $1530 \mathrm{~cm}^{-1}$ are corresponded to the ill-organized graphitic (mode D-band) due to structural imperfections or impurities and the tangential $\mathrm{C}-\mathrm{C}$ stretching vibration (mode G-band) due to integrity of hexagonal carbon [33] respecively. Ratio intensity of $\mathrm{D}$ and $\mathrm{G}$ band, $\left(\mathrm{I}_{\mathrm{D}} / \mathrm{I}_{\mathrm{G}}\right)$ are very important factors to distinguish the three different structural nanotubes (Table 1). The relative stronger G-band of CNT pristine decreases after purification. After purification, relative intensity ratio $\left(\mathrm{I}_{\mathrm{D}} / \mathrm{I}_{\mathrm{G}}\right)$ tend to decrease from 0.95 to 0.76 due to removal of impurities from carbon surface. High ratio $\left(\mathrm{I}_{\mathrm{D}} / \mathrm{I}_{\mathrm{G}}\right)$ of functionalized MWCNT (1.68) compared with that of purified MWCNT (0.76) shows decreasing symmetry in the functionalized MWCNT structure due to introduction of functional groups to carbon surface. Tsukahara et al. [20] and Dasyuk et al., [34] resulted in ratio $\left(\mathrm{I}_{\mathrm{D}} / \mathrm{I}_{\mathrm{G}}\right) 1.45$ and 1.01 after oxidation of MWCNT with nitric acid $70 \%$ under microwave radiation and reflux in $65 \%$ nitric acid for 48 hours, respectively. This describes that the acid-treatments do not totally damage the structural ordering of MWNTs. Analysis of nanotube diameter could not be evaluated because of weak observable radial breathing mode of MWCNT, elucidating the large diameter of carbon fibers.

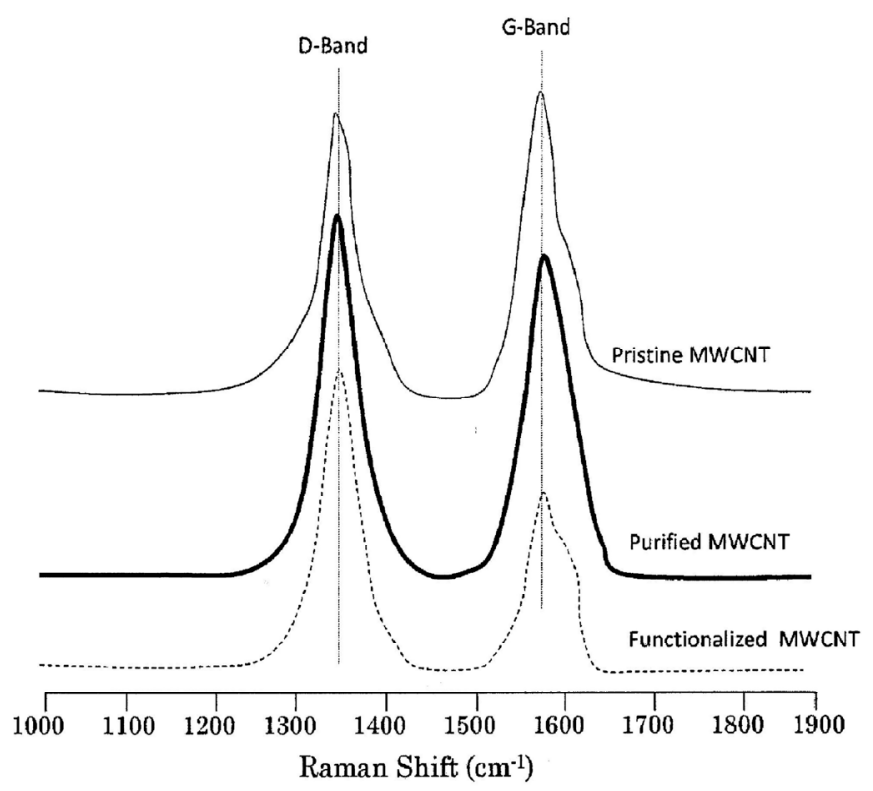

Fig. (4). Raman spectra of pristine and acid treated MWCNTs. $(\longrightarrow$ pristine MWCNT, $\longrightarrow$ purified MWCNT, --functionalized MWCNT).

\section{CONCLUSIONS}

Integrated analysis of functional group attached on the MWCNT surface has been conducted. All analysis reveal that functionalization process causes a cutting off carbon double bonding generating asymetrical hexagonal carbon and defect on the side-wall. Shortening fiber allows functional groups to stick on the fiber surface and at the end of fiber. Density of carboxyl and total acidic sites strongly depend on the power of acid solution whereas carboxyl groups was dominantly introduced on the carbon nanotube surface. Stepwise purification also causes increasing graphitization as well as a partial oxidation of carbon.

\section{REFERENCES}

[1] Iijima S. Helical microtubules of graphitic carbon. Nature 1991; 354: 56-8.

[2] Merkoci A, Pumera M, Llopis X, P'erez B, Del Valle M, Alegret S. New materials for electrochemical sensing. VI. Carbon nanotubes. TRAC Trends Anal Chem 2005; 24: 826-38.

[3] Ajayan PM. Nanotubes from carbon. Chem Rev 1999; 99: 17871800 .

[4] Katz E, Willner I. Biomolecule-functionalized carbon nanotubes: applications in nanobioelectronics. Chem Phys Chem 2004; 5: 1085-104.

[5] Orlanducci S, Sessa V, Terranova ML, Battiston GA, Battiston S, Gergasi R. Nanocrystalline $\mathrm{TiO} 2$ on singled walled carbon nanotube arrays : toward the assembly of organized $\mathrm{C} / \mathrm{TiO}_{2}$ nanosystem. Carbon 2006; 44: 2839-43. 
[6] Ciraci S, Dag S, Yildirim T, Gülseren O, Senger RT. Functionalized carbon nanotubes and device applications. J Phys Condens Matter 2004; 16: R901-60.

[7] Wang QH, Yan M, Chang RPH. A flat panel display prototype using gated carbon nanotube field emitters. Appl Phys Lett 2001; 78: 1294-96

[8] Karousis N, Tsotsou GE, Evangelista F, Rudolf P, Ragoussis N, Tagmatarchis $N$. Carbon nanotubes decorated with palladium nanoparticles: Synthesis, characterization, and catalytic activity. J Phys Chem C 2008; 112: 13463-9.

[9] Martinez-Rubi Y, Guan JW, Lin SQ, Scriver C, Sturgeon RE, Simard B. Chem Commun 2007; 48: 5146-8.

[10] Thess A, Lee R, Nikolaev P, et al. Crystalline ropes of metallic carbon nanotubes. Science 1996; 273: 483-7.

[11] Liu J, Rinzler AG, Dai H, et al. Fullerene pipes. Science 1998; 280: 1253-6.

[12] Zhang H, Li HX, Cheng HM. Water-soluble multiwalled carbon nanotubes functionalized with sulfonated polyaniline. J Phys Chem B 2006; 110: 9095-9.

[13] Hirsch A. Functionalization of single-walled carbon nanotubes. Angew Chem Int 2002: 1853-9.

[14] Shi D, Lian J, He P, et al. Plasma deposition of ultrathin polymer film on carbon nanotube. Appl Phys Lett 2002; 81: 5216-8.

[15] Shi D, Lian J, He P, Wang PM, Schultz M, Mast DB. Plasma coating of carbon nanofibers for enhanced dispersion and interfacial bonding in polymer composites. Appl Phys Lett 2003; 83: 5301-3.

[16] Boudou JP, Paredes JI, Cuesta A, Martinez-Alonso A, Tascon JMD. Oxygen plasma modification of pitch-based isotropic carbon fiber. Carbon 2003; 41: 41-56.

[17] Xie F, Philips J. Silva IF, Palma MC, Menendez JA. Microcalorimetric study of acid sites on ammonia and acidpretreate activated carbon. Carbon 2000; 38: 691-700.

[18] $\mathrm{Hu}$ CC, Wang CC. Effects of electrolytes and electrochemical pretreatments on the capasitiive characteristic of activated carbon fabrics for supercapacitors. J. Power Source 2004; 125: 299-308.

[19] Huang W, Wang Y, Luo G, Wei F. 99.9\% Purity multi-wall carbon nanotube by vacuum temperature high annealing. Carbon 2003; 41 : 2585-90.

[20] Tsukahara Y, Yamauchi T, Kawamoto T, Wada Y. Functionalization of multi-walled carbon nanotubes realized by microwave-driven chemistry inducing dispersibility in liquid media. Bull Chem Soc Jpn 2008; 81: 387-92.
[21] Ziegler KJ, Gu Z, Peng H, Flor EL, Hauge RH, Smalley RE. Controlled oxidative cutting of single-walled carbon nanotubes. J Am Chem Soc 2005; 127: 1541-7.

[22] Ziegler KJ, Gu Z, Shaver J, et al. Cutting single-walled carbon nanotubes. Nanotechnology 2005; 16: S539-44.

[23] Liu J, Rinzler AG, Dai HJ, et al. Fullerene pipe. Science 1998; 280: 1253-6

[24] Zhang J, Zou H, Qing Q, et al. Effect of chemical oxidation on the structure of single-walled carbon nanotubes. J Phys Chem B 2003 107: 3712-8.

[25] Chen RJ, Zhang Y, Wang D, Dai H. Noncovalent sidewall functionalization of single-walled carbon nanotubes for protein immobilization. J Am Chem Soc 2001; 123: 3838-9.

[26] Vesali NM, Khodadadi AA, Mortazavi Y, et al. Functionalization of carbon nanotubes using nitric acid oxidation and DBD plasma. World Academy of Science, Engineering and Technology 2009; 49: 177-9.

[27] Chen S, Shen W, Wu G, Chen D, Jiang M. A new approach to functionalization of single-walled carbon nanotube with both alkyl and carbonyl groups. Chem Phys Lett 2005; 402: 302-17.

[28] Lee SY, Park SJ. Hydrogen adsorption of acid-treated multi-walled carbon nanotubes at low temperature. Bull Korean Chem Soc 2010 31: 1596-1600.

[29] Lin W, Xiu Y, Zhu L, Moon KS, Wong CP. Assembling of carbon nanotube structures by chemical anchoring for packaging applications. Electronic Components and Technology Conference 2008; 421-6.

[30] Boehm HP. Some aspects of the surface chemistry of carbon blacks and other carbons. Carbon 1994; 32: 759-69.

[31] László K, Josepovits K, Tombácz E. Analysis of active sites on synthetic carbon surfaces by various methods. Anal Sci 2001; 17 i1741-i4

[32] González-Guerrero AB, Mendoza E, Pellicer E. Discriminating the carboxylic groups from the total acidic sites in oxidized multi-wall carbon nanotubes by means of acid-base titration. Chem Phys Lett 2008; 462: 256-9.

[33] Pierard N, Fonseca A, Colomer JF, et al. Ball milling effect on the structure of single-wall carbon nanotubes. Carbon 2004; 42: 16917.

[34] Dasyuk V, Kalyva M, Papagelis K, et al. Chemical oxidation of multiwalled carbon nanotube. Carbon 2008; 46: 833-40.

This is an open access article licensed under the terms of the Creative Commons Attribution Non-Commercial License (http://creativecommons.org/licenses/by-nc/3.0/) which permits unrestricted, non-commercial use, distribution and reproduction in any medium, provided the work is properly cited. 